\title{
Let Us Eradicate All Bias, Gender Included
}

Given our profession, we understand the what, why, and how of the human body better than most others. Despite the advances within and outside the test tube, there has to be a man and a woman to take the species forward. The need being so fundamentally biological, neither gender has a logical reason to nurture a bias against the other. Yet gender bias is one of the cancerous issues we face today.

Recently, one of our colleagues participated in a meeting that mooted a separate forum for women oncologists in India. ${ }^{[1]}$ Yes, one oncologist could be more skilled and experienced than another, but what has gender got to do with it? Why did she and others feel the need for such a forum? What is the reality and current status of gender bias in the elites of oncology? A quick survey of oncologists done by the authors revealed that the bias is for real and yet, it is not as alarming as one would have feared.

\section{Survey Findings}

In all, 113 oncologists responded to the survey, with $71 \%$ of them being men. As much as $60 \%$ of the respondents were at least 40 years of age. While $51 \%$ felt that gender bias was for real and women suffered more, $7 \%$ were of the opinion that men suffered more. A significant number, $38 \%$, did not think that there was any gender bias [Figure 1].

They cited, in reducing order of frequency, denial of opportunity, harassment (physical and/or mental), neglect, and inequality in remuneration as manifestations of bias [Figure 2]. While most named the community (including patients) as the source of bias, colleagues and hospital administrators were next in order of villainy [Figure 3].

On a positive note, $26 \%$ were able to overcome the bias, while 35\% succeeded partially ("but it's difficult").

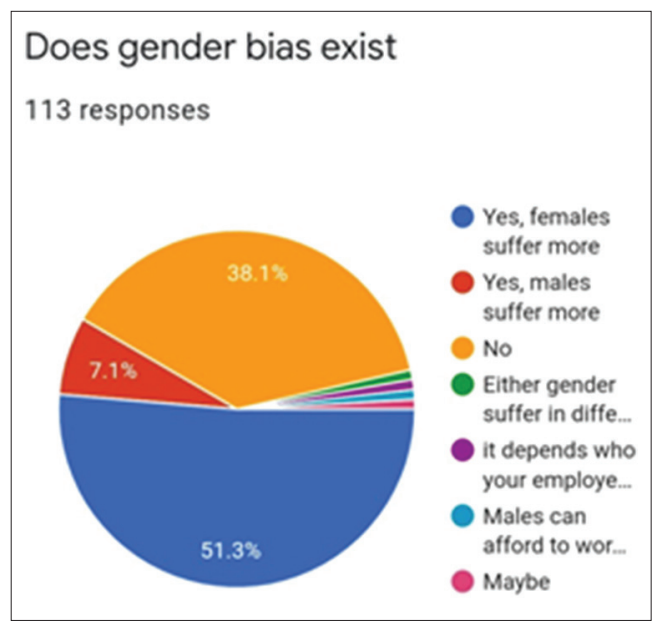

Figure 1: Does gender bias exist
Unfortunately, 15\% were beyond caring and 4\% admitted to being frustrated. Significantly, $20 \%$ chose not to answer if they could overcome the bias [Figure 4].

A majority of the respondents were medical oncologists $(65 \%)$, followed by surgical oncologists $(23 \%)$, radiation oncologists $(7 \%)$, and students $(2 \%)$.

Most of them (31\%) blamed the regressive attitude of the community as the primary cause of gender bias, with a "supremacist mindset" ranked right behind (25\%). While $12 \%$ pointed a finger at disrespect for the opposite sex, $7 \%$ thought it was due to lack of education [Figure 5].

Creating community awareness was the most preferred $(46 \%)$ solution, while better education at school level was recommended by $33 \%$. Watchdogs to monitor the situation at institutions would help (11\%) and optimal punishment to culprits (5\%) could be effective [Figure 6].

When asked to rank the probability of the gender bias problem being resolved, as much as $79 \%$ were optimistic (ranked 6 or more). Two (out of the 113 respondents) did not have any hope (rank 0), while 15 were most confident (rank 10).

\section{A Global Issue}

It would appear that gender bias is a problem that prevails across countries and professions. Let's start with the same issue that our survey addressed: gender bias among oncologists.

Back in 2016, the European Society for Medical Oncology Women for Oncology (W4O) Committee had undertaken a similar survey ${ }^{[2]}$ of female and male oncologists, and 462 had responded $(77 \%$ of women). The survey revealed that men $(65 \%$ vs. $46 \%)$ were more likely to have leadership

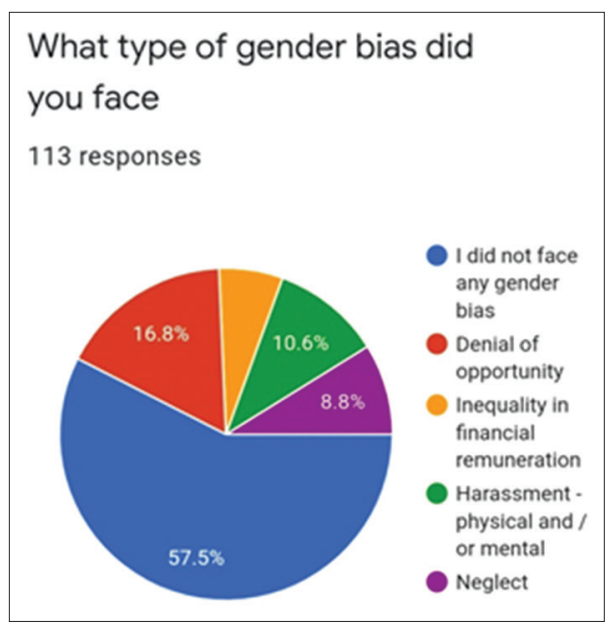

Figure 2: Type of gender bias faced 


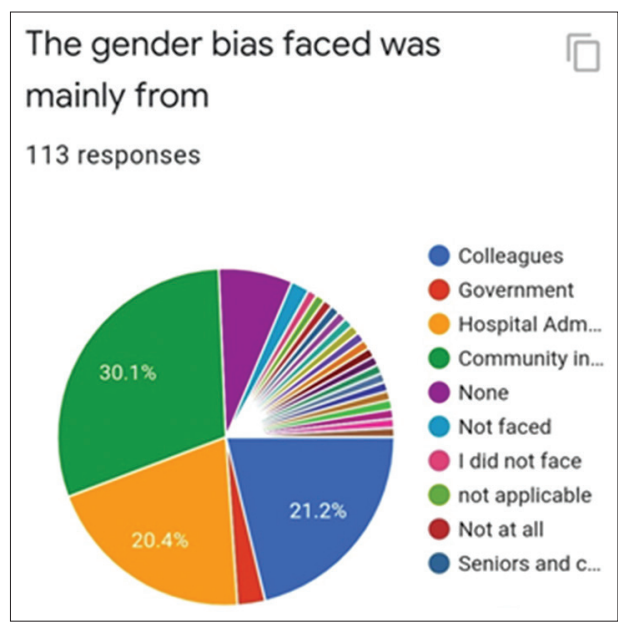

Figure 3: Bias was at the hands of: Who caused the bias?

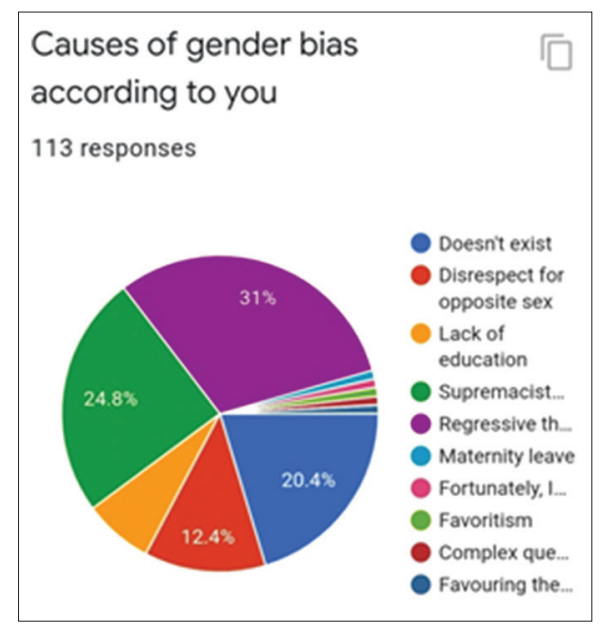

Figure 5: Causes of gender bias

roles, even in clinical teams with more women than men. Female respondents were more likely to consider that their gender had a major impact on their career than male respondents (36\% vs. $21 \%$ ). The biggest challenge to career progression for women was work and family balance (64\%). Among the women, 38\% reported that they had encountered unwanted sexual comments by a superior or colleague. On compensation, only $14 \%$ of the female respondents believed that there had been a significant or major progress in closing the gender pay gap compared to $39 \%$ of men.

One study ${ }^{[3]}$ presented at the 2019 annual meeting of the American Society of Clinical Oncology (ASCO), based on anonymous telephone interviews with 17 hematology and oncology fellows, observed that incidents of discrimination toward fellows were common, and there were more perpetrators among the patients than the staff.

An analysis $^{[4]}$ of 781 presentations from the 2017 and 2018 ASCO Annual Meeting video archives showed that women were less likely to receive a professional form of address compared to men (61\% vs. $81 \%$ ). In addition, women were more likely to be introduced by first name

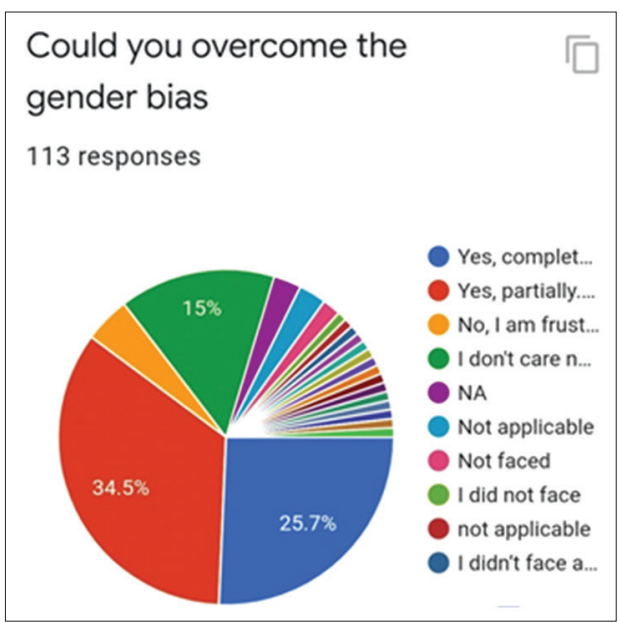

Figure 4: Could you overcome bias

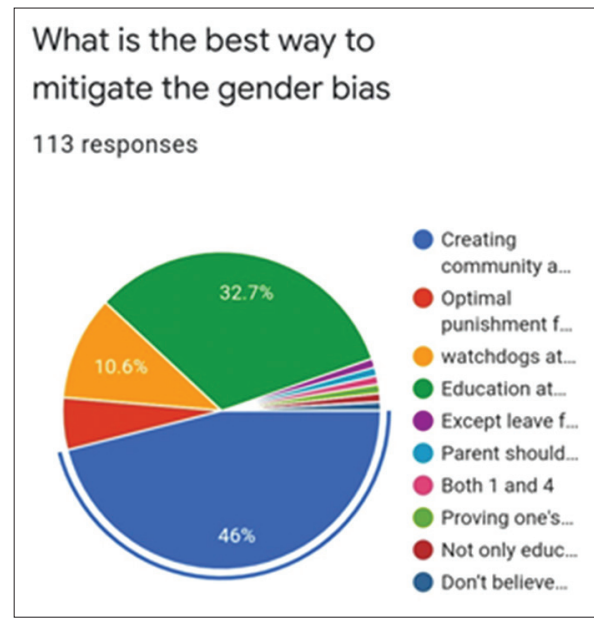

Figure 6: The best way to mitigate gender bias

only (17\% vs. $3 \%)$. While women who introduced speakers were more likely to use their professional title, regardless of gender, men were more likely to introduce women by first name only.

\section{Bias in Other Professions}

A 2018 study $^{[5]}$ by the Center for WorkLife Law at the University of California for the American Bar Association's Commission on Women in the Profession and others indicated that there was widespread gender and racial bias in hiring, promotion, assignments, and compensation in the legal industry. As much as 58\% of women attorneys of color and $50 \%$ of caucasian lawyers stated that they were mistaken for administrative staff or janitors. In contrast, only $7 \%$ of caucasian lawyers reported a similar problem.

A more recent study ${ }^{[6]}$ by the State of Women in Engineering of 700 engineers (60\% women) working in India for Western companies, with an experience of at least 2 years, reported that both male and female engineers were facing bias. Over $75 \%$ reported bias in decisions about promotion, 
sponsorship, mentoring, and compensation. A slightly smaller number $(67 \%)$ reported bias in performance evaluations. More than $50 \%$ felt excluded by their colleagues and did not feel they belonged to their organizations.

It is interesting that $7 \%$ of the respondents to the survey of the oncology community (cited in the beginning) had reported that men suffered more on account of bias. That probably calls for a survey that looks into factors other than gender.

\section{Gender or Else, Rise Above Bias}

Obviously, regardless of their specialization, doctors are human and are therefore susceptible to bias. While there is no need to deny this diagnosis, there is no need to be overwhelmed by it either.

Oncologists routinely battle cancers that eat away anatomy and impair physiology. It is a matter of extending their skill to diagnose and eliminate the bias carcinoma of the mindset.

A separate forum need not be simply a symptom of the problem; rather, it could bring about greater efficiency and faster development of the profession.

If some form of bias cannot be eliminated, maybe it is best to cultivate a bias for skill and compassion.

\section{Padmaj S Kulkarni', Amrita Prayag', Anupama Shirish Borker ${ }^{2}$, Bhawna Sirohi ${ }^{3}$ \\ ${ }^{\prime}$ Deenanath Mangeshkar Hospital and Research Centre, Pune, Maharashtra, India, ${ }^{2}$ Department of Medical Oncology, Goa Medical College, Bambolim, Goa, India, ${ }^{3}$ Department of Medical Oncology, Deenanath Mangeshkar Hospital, Pune, Maharashtra, India}

Address for correspondence: Dr. Padmaj S Kulkarni, Deenanath Mangeshkar Hospital and Research Centre, Pune - 411004 , Maharashtra, India. E-mail: padmaj.kulkarni@gmail.com
Submitted: 11-Mar-2020

Accepted in Revised Form: 12-Mar-2020

Published: 24-Apr-2020

\section{References}

1. Parikh BS. Woman oncologist's perspective. Indian J Med Paediatr Oncol 2020;41:64-5.

2. Banerjee S, Dafni U, Allen T, Arnold D, Curigliano G MD, Garralda E, et al. Gender-related challenges facing oncologists: The results of the ESMO Women for Oncology Committee survey. ESMO Open 2018;3:e00422.

3. Available from: https://meetinglibrary.asco.org/ record/173416/. [Last accessed on $2020 \mathrm{Feb} 08$ ].

4. Available from: https://meetinglibrary.asco.org/record/173397/. [Last accessed on $2020 \mathrm{Feb}$ 08].

5. Available from: https://www.americanbar.org/content/dam/aba/ administrative/women/you-cant-change-what-you-cant-see-print. pdf. [Last accessed on 2020 Apr 05].

6. Available from: https://alltogether.swe.org/2019/04/a-look-atgender-bias-in-india/. [Last accessed on 2020 Feb 08].

This is an open access journal, and articles are distributed under the terms of the Creative Commons Attribution-NonCommercial-ShareAlike 4.0 License, which allows others to remix, tweak, and build upon the work non-commercially, as long as appropriate credit is given and the new creations are licensed under the identical terms.

\begin{tabular}{|l|l|}
\hline \multicolumn{2}{|c|}{ Access this article online } \\
\hline Quick Response Code: & Website: \\
& www.ijmpo.org \\
\cline { 2 - 2 } & DOI: \\
\hline
\end{tabular}

How to cite this article: Kulkarni PS, Prayag A, Borker AS, Sirohi B. Let us eradicate all bias, gender included. Indian J Med Paediatr Oncol 2020;41:1-3. 